\title{
Potential Thyrotropic and Antihypercholesteronemic Activity Exhibited by Ethanolic Extract of Crataeva nurvala Bark
}

\author{
Arshvir Kaur $^{1 *}$, Navneet Khurana ${ }^{2}$, Santosh Kumar Verma ${ }^{3}$ \\ ${ }^{1}$ Department of Pharmacology, School of Pharmaceutical Sciences, Lovely Professional University, Phagwara, Punjab, India. \\ ${ }^{2}$ Department of Pharmacology and Pharmacognosy, School of Pharmaceutical Sciences, Lovely Professional University, Phagwara, Punjab, India. \\ ${ }^{3}$ Department of Pharmacology, CT Institute of Pharmaceutical Sciences, Shahpur, Jalandhar, Punjab, India.
}

\begin{tabular}{|c|c|}
\hline ARTICLE INFO & ABSTRACT \\
\hline Article history: & \multirow{10}{*}{$\begin{array}{l}\text { Charaka, supports that the imbalance (Ojus) between the three bodily humours (doshas), along with the fat } \\
\text { (Meda) leads to enlargement of the thyroid gland (Galaganda) and metabolic syndrome. This study aims to } \\
\text { evaluate the effect of the ethanolic extract of Crataeva nurvala (CNet) bark, on free thyroxine }\left(\mathrm{FT}_{4}\right) \text {, thyroid } \\
\text { stimulating hormone (TSH) and serum cholesterol }(\mathrm{CHO}) \text { in Swiss albino female adult mice over conventional } \\
\text { therapy. In this study, the animals were divided into four groups who were made hypothyroid using } 6 \text {-propyl-2- } \\
\text { thiouracil (PTU) for first } 15 \text { days and then Group I, treated with vehicle, Group II, treated with } \mathrm{LT}_{4}(14.56 \\
\mu \mathrm{g} / \mathrm{kg} \text { ), Group III, treated with CNet } 400 \mathrm{mg} / \mathrm{kg} \text { and Group IV treated with CNet } 600 \mathrm{mg} / \mathrm{kg} \text { (p.o.) for another } \\
15 \text { days. The variation in the biochemical parameters was recorded on Day } 15^{\text {th }} \text { and Day } 30^{\mathrm{th}} \text {. The results were } \\
\text { expressed as mean } \pm \mathrm{SEM} \text {, using two-way ANOVA followed by Bonferroni posttests. In comparison with the } \\
\text { standard i.e. } \mathrm{LT}_{4} \text {, significant (***P } P 0.001 \text { ) thyroid stimulant activity was shown by CNet } 600 \mathrm{mg} / \mathrm{kg} \text {, with } \\
\text { significant reduction in cholesterol levels whereas, less marked and erratic response with CNet } 400 \mathrm{mg} / \mathrm{kg} \text { was } \\
\text { received. Crataeva nurvala was found effective at higher dose, that suggest its beneficial role in treating } \\
\text { hypothyroidism and associated hypercholesteronemia. }\end{array}$} \\
\hline Received on: 08/10/2017 & \\
\hline Accepted on: 11/11/2017 & \\
\hline Available online: $30 / 11 / 2017$ & \\
\hline Key words: & \\
\hline Varuna, thyroxine, & \\
\hline cholesterol, thyroid & \\
\hline stimulating hormone, & \\
\hline & \\
\hline & \\
\hline
\end{tabular}

\section{INTRODUCTION}

Levothyroxine $\left(\mathrm{LT}_{4}\right)$ is the standard replacement therapy in hypothyroidism, clinically that offers a similar life quality, whereas the psychological well being is compromised (Garber et al., 2012; Petersen et al., 1990; Jonklaas et al., 2008; Saravanan et al., 2002). Also, many physiological and pathological conditions can impair $\mathrm{LT}_{4}$ absorption such as patient factors (compliance), certain foods (e.g. Grapes, coffee, soyabean, papaya etc.), age factor, drugs (e.g. Antacids containing aluminium, sucralfate, proton pump inhibitors,

\footnotetext{
* Corresponding Author

Arshvir Kaur, Domain- Pharmacology School of Pharmaceutical Sciences, Lovely Professional University, Jalandhar-Delhi G.T. Road (NH-1), Phagwara, Punjab, India.Email: archie.dhwal @ gmail.com Mobile: +91-9855518759
}

rifampicin, antiepileptics, etc.) gastrointestinal diseases (e.g. Helicobacter pylori infection, celiac disease). The principal adverse consequences of overtreatment are TSH suppression cardiovascular risk, skeletal or high risk of fracture, especially postmenopausal women, however, bone density does not reduce on short term administration and possible affective disturbances (Rees-Jones and Larsen, 1977; Razvi et al., 2012; Schneider et al., 2012; Ross, 1993; Biondi et al., 1994; Botella-Carretero et al., 2003).

Crataeva nurvala Buch-Ham, belonging to the family, Capparidaceae, synonymously called as C. magna (Lour.) DC., C. religiosa Hook. F and Varuna (Khare, 2007; Daniel, 2006). It is reported to possess analgesic, neuroprotective, antiarthiritic, anticancer, antidiabetic, cardioprotective, anti-inflammatory, antioxidant, hepatoprotective, nephroprotective activities (Khattar and Wal, 2012). 
In Ayurveda, thyroid disorders are discussed under the term "Galaganda" (enlarged thyroid gland). Ayurveda supports use of Varuna leaves, stem bark and root bark in regulating equilibrium among three doshas (bodily humours) Vata (air), Pitta (earth) and Kapha (mucous or water), whose imbalance leads to hormonal imbalance (Ojus), most commonly thyroid disorders (Kaur et al., 2016). Traditionally it is also believed to be used for treating cancer, paralysis, thyroid problems etc. (Narayana and Subhose, 2005). So, it was hypothesized that this plant can have beneficial effects in hypothyroidism.

To the best of our knowledge, no scientific data regarding the thyrotropic activity of ethanolic extract of $C$. nurvala bark (CNet) in preclinical studies in hypothyroid mice is published. This study aimed to evaluate the thyrotropic and antihypercholesterolemic effect of the CNet in mice, whose thyroid status was disrupted by using (6-propyl-2-thiouracil) PTU, an antithyroid drug, that inhibit the thyroid gland and decline the thyroid hormone synthesis via inhibiting thyroid peroxidase (TPO), iodothyronine deiodinases type I (DIO1) and inhibiting thyroid receptor (TR) mediated transcriptional activities by dissociating the nuclear coactivators and by recruitment of corepressors present at the glandular levels thus causing primary hypothyroidism i.e. reducing the levels of $\mathrm{FT}_{4}$ with concomitant increase in TSH (Moriyama et al., 2007).

\section{MATERIAL AND METHODS}

\section{Chemicals}

6-Propyl-2-thiouracil (PTU), was supplied by SigmaAldrich Chemeie GmbH, Levothyroxine Sodium Tablets (Eltroxin-GSK) and all the other chemicals used in extraction and phytochemical screening were of reagent grade.

\section{Animals}

Swiss Albino female mice, aged between 3-5 months weighing 25-35 g, procured from Panacea Biotec Ltd, Lalru (140501), India and were housed in polypropylene cage, kept standard laboratory conditions (temperature $25 \pm 2^{\circ} \mathrm{C}$, relative humidity $30-70 \%$ with $12 / 12 \mathrm{~h}$ night/dark cycle), were fed with standard pellet diet procured from Shree Jagdambey Feed Industries, Moga, Punjab and water ad libitum for acclimatization period of one week before study.

\section{Ethical approval}

The study protocol was duly approved by the Institutional Animal Ethics Committee (IAEC) [Protocol no.: IAEC-CTIPS/2015/VII/0042 (PCL-M)] of the Institute under the guideline of the Committee for the Purpose of Control and Supervision of Experiments on Animals (CPCSEA), Ministry of Environment \& Forests, New Delhi.

\section{Procurement and preparation of the CNet}

The dried stem bark of $C$. nurvala $(3.5 \mathrm{~kg})$ was procured from Herbal Health Research Consortium Pvt. Ltd. Amritsar (Lot
No. VRN-024, Certificate of Analysis A. R. No. 06/2015/IH/086, in compliance with Q.S.I.M.P. Volume 10, Page no. 106-108). A voucher (HHRC/RT/0416/15-16) and plant specimen has been submitted to the department of Pharmacology, of our college for future reference.

The bark extract was prepared using a repeated maceration technique (Hussain et al., 2013). The shade dried bark of $C$. nurvala $(3.5 \mathrm{~kg})$ was rendered dust free and the size was reduced. The coarse powdered material (mesh \#16) was macerated with $95 \%$ ethanol ( $1 \mathrm{~kg}$ in 3 1), the soaked material was strained through a double layered muslin cloth and the marc was pressed. The two filtrates were then combined and then clarified by filtering through Whatman No. 1 filter paper. This process was repeated every third day for 12 days. The filtrates from the four macerations were then combined and the solvent was recovered under vacuum at $37^{\circ} \mathrm{C}$ and the extract was concentrated to obtain brown pasty mass. The percentage yield was found to be $1.37 \%$. The suspension $(20 \mathrm{mg} / \mathrm{ml})$ is prepared with $1 \%$ of Gum Acacia solution and stored at $2-8^{\circ} \mathrm{C}$ in amber colored bottle.

\section{Phytochemical screening}

The phytochemical identification of CNet was carried out using qualitative test like Keller-Killiani test, lead acetate test, sodium hydroxide test, silver nitrate test, Salkowski test, Lieberman's test, froathing test etc.

\section{Evaluation of thyrotropic activity of C.nurvala in PTU induced hypothyroidism}

Mice of 25-35 $\mathrm{g}$ were divided into four groups, administered PTU (10 mg/kg orally) for 15 days and then treated with vehicle, standard and test drug for next 15 days (Panda and Kar, 2005).

Group I, PTU (10 mg/kg) + VEH (Negative control)

Group II, PTU $(10 \mathrm{mg} / \mathrm{kg})+\mathrm{LT}_{4}(14.56 \mu \mathrm{g} / \mathrm{kg})$

(Standard)

Group III, PTU (10 mg/kg) + CNet $400 \mathrm{mg} / \mathrm{kg}$

Group IV, PTU (10 mg/kg) + CNet $600 \mathrm{mg} / \mathrm{kg}$

C. nurvala has shown promising hypocholesteronemic activity in other animal model, moreover, literature sources support its neuroprotective, hepatoprotective and nephroprotective activities at different doses. However, two dose levels i.e. 400 and $600 \mathrm{mg} / \mathrm{kg}$ were evaluated in this study (Sikarwar and Patil, 2012; Bhattacharjee et al., 2014; Panda et al., 2014; Shelkea et al., 2011).

The variation in the $\mathrm{FT}_{4}, \mathrm{TSH}$ and $\mathrm{CHO}$ were analyzed via comparing Day $15^{\text {th }}$ with Day $30^{\text {th }}$ results in individual groups. Dosage administration was done every day between 9.00 am to $10.00 \mathrm{AM}$ to avoid circadian variation.

\section{Serum preparation}

Blood sampling was done after 24 hours of the last dose on Day $15^{\text {th }}$ and Day $30^{\text {th }}$ via retro-orbital method. The samples were allowed to clot at room temperature and then centrifuged for 
$20 \mathrm{~min}$ to separate the serum. The serum samples were stored at $20^{\circ} \mathrm{C}$ to $-80^{\circ} \mathrm{C}$ until assayed for biochemical investigations.

\section{Biochemical estimation in serum}

Serum $\mathrm{FT}_{4}$, TSH was determined by ELISA as per the provided protocol by ERBA Lachema s.r.o., Czech Republic and Calbiotech Inc., Austin, CA on Day $15^{\text {th }}$ and Day $30^{\text {th }}$. Serum $\mathrm{CHO}$ levels were determined using ERBA Mannheim $\mathrm{GmbH}$, Germany autoanalyser kit.

\section{Statistical analysis}

The results are expressed as mean \pm SEM, $(n=6)$, Where $* * * P<0.001, * * P<0.01$ and $* P<0.05$ (PTU $+\mathrm{VEH}$ as control at Day $30^{\text {th }}$ ) and ${ }^{\# \# \#} P<0.001,{ }^{\# \#} P<0.01$ and ${ }^{\#} P<0.05$ (PTU+LT4 as control at Day $30^{\text {th }}$ ) for serum biochemical estimation, using Two-way RM ANOVA followed by a Bonferroni post test to compare replicated means by row in each column representing different points of time.

\section{RESULTS}

\section{Phytochemical analysis}

The CNet was screened for preliminary phytochemical identification tests which revealed the presence of mainly cardiac glycosides, flavonoids, alkaloids, terpenoids and saponins.

\section{Effect on $\mathrm{FT}_{4}$}

The administration of PTU, an antithyroid drug for 15 days in all groups, was associated with low serum $\mathrm{FT}_{4}$ levels, that significantly rose with the administration of standard drug, $\mathrm{LT}_{4}$ i.e. $2.343 \mathrm{ng} / \mathrm{dl}(* * P<0.01)$, test drugs CNet 400 and CNet 600 i.e. $3.258 \mathrm{ng} / \mathrm{dl}$ and $3.709 \mathrm{ng} / \mathrm{dl} \quad(* * * P<0.001)$ at day $30^{\text {th }}$ in comparison with PTU+VEH. Rise in $\mathrm{FT}_{4}$ in PTU+CNet 600 was even considerably higher than standard, i.e.PTU+LT $4\left({ }^{\#} P<0.05\right)$ (Table 1, Figure 1).

\section{Free Thyroxine $\left(\mathrm{FT}_{4}\right)$}

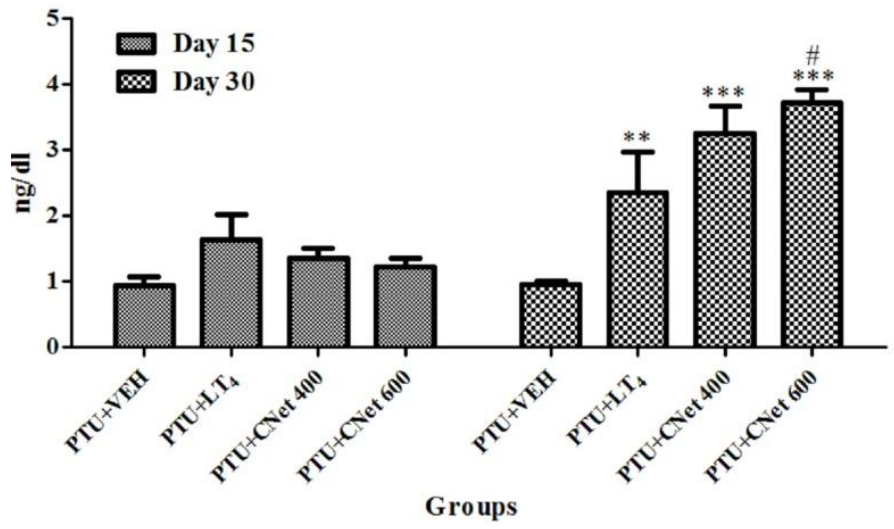

Fig. 1: Effect of C.nurvala on free thyroxine

The results are expressed as mean \pm SEM, $(\mathrm{n}=6)$, Where $* * * P<0.001$ and ${ }^{* *} P<0.01$ (PTU+VEH as control at Day $30^{\text {th }}$ ) and ${ }^{\#} P<0.05$ (PTU+LT 4 as control at Day $30^{\text {th }}$ ), using Two-way RM ANOVA followed by a Bonferroni post test.

\section{Effect on TSH}

The administration of PTU for 15 days led to increase in TSH levels in PTU+VEH and PTU+CNet 600, whereas less rise was observed in other two groups. The administration of CNet 600 declined significantly the levels of TSH in PTU+CNet 600 $(* P<0.05)$ i.e. $0.209 \mu \mathrm{IU} / \mathrm{ml}$ w.r.t PTU+VEH, but the levels were found to be raised in an erratic pattern in PTU+CNet 400 $\left({ }^{\#} P<0.05\right)$ in comparison with standard group (Table 1, Figure 2). However, the administration of vehicle and $\mathrm{LT}_{4}$ showed no significant change in levels of TSH in PTU+VEH and PTU+LT $\mathrm{P}_{4}$ at day $30^{\text {th }}$.

\section{Thyroid Stimulating Hormone (TSH)}

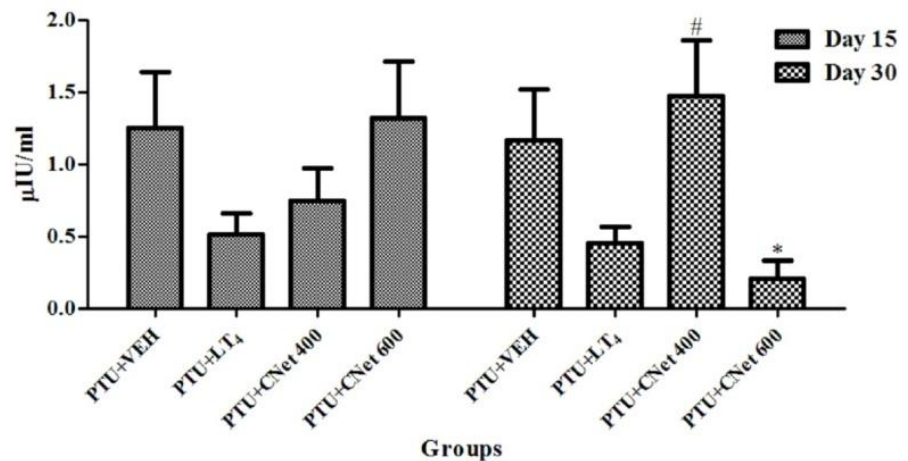

Fig 2: Effect of C.nurvala on thyroid stimulating hormone

The results are expressed as mean \pm SEM, $(n=6)$, Where $* P<0.05$ (PTU+VEH as control at Day $30^{\text {th }}$ ) and ${ }^{\#} P<0.05$ (PTU+LT 4 as control at Day $30^{\text {th }}$ ), using Two-way RM ANOVA followed by a Bonferroni post test.

\section{Effect on CHO}

The administration of PTU elevated the levels of cholesterol, that found to be less in PTU+CNet 400 and PTU+CNet 600, w.r.t. negative control $(* * * P<0.001)$ and standard group i.e. $36.578 \mathrm{mg} / \mathrm{dl}\left({ }^{\# \#} P<0.01\right)$ and $29.585 \mathrm{mg} / \mathrm{dl}\left({ }^{\# \#} P<0.001\right)$ at Day $30^{\text {th }}$ (Table 1, Figure 3). However, the levels elevated in PTU+VEH and PTU+LT 4 .

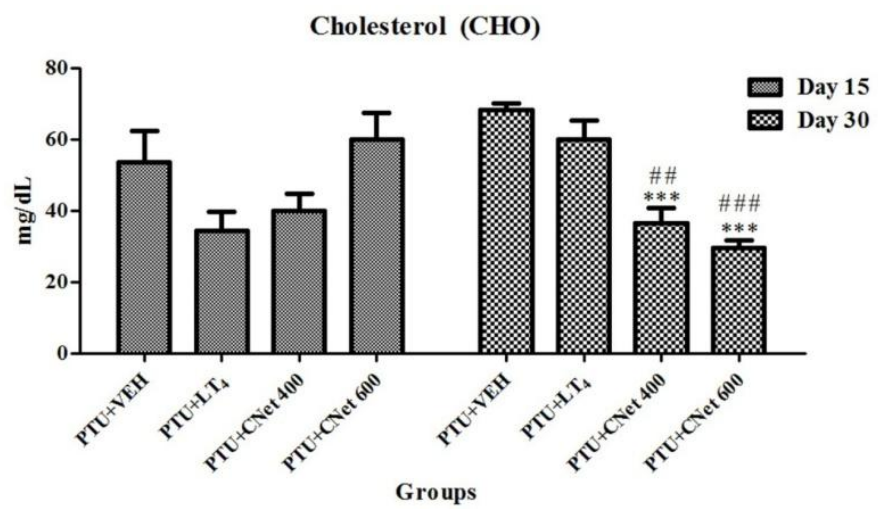

Fig 3: Effect of C.nurvala on cholesterol

The results are expressed as mean \pm SEM, $(n=6)$, Where $* * * P<0.001$ (PTU+VEH as control at Day $\left.30^{\text {th }}\right)$ and ${ }^{\# \#} P<0.001$ and ${ }^{\# \#} P<0.01\left(\mathrm{PTU}+\mathrm{LT}_{4}\right.$ as control at Day $30^{\text {th }}$ ), using Two-way RM ANOVA followed by a Bonferroni post test. 
Table 1: Effect of C. nurvala on thyroid parameters and cholesterol in hypothyroid mice at day $15^{\text {th }}$ and $30^{\text {th }}$.

\begin{tabular}{|c|c|c|c|c|c|}
\hline \multicolumn{2}{|c|}{ Groups } & \multirow{2}{*}{ PTU+VEH } & \multirow{2}{*}{$\mathbf{P T U}+\mathbf{L T}_{4}$} & \multirow{2}{*}{ PTU+CNet 400} & \multirow{2}{*}{ PTU+CNet 600} \\
\hline Parameter & Day & & & & \\
\hline \multirow[b]{2}{*}{$\mathrm{FT}_{4}(\mathrm{ng} / \mathrm{dl})$} & 15 & $0.941 \pm 0.119$ & $1.630 \pm 0.379$ & $1.354 \pm 0.142$ & $1.221 \pm 0.136$ \\
\hline & 30 & $0.946 \pm 0.055$ & $2.343 \pm 0.626^{* *}$ & $3.258 \pm 0.411^{* * *}$ & $3.709 \pm 0.204 * * * \#$ \\
\hline \multirow{2}{*}{ TSH $(\mu \mathrm{IU} / \mathrm{ml})$} & 15 & $1.256 \pm 0.387$ & $0.512 \pm 0.145$ & $0.747 \pm 0.230$ & $1.319 \pm 0.392$ \\
\hline & 30 & $1.168 \pm 0.353$ & $0.451 \pm 0.113$ & $1.340 \pm 0.368 \#$ & $0.209 \pm 0.124 *$ \\
\hline \multirow{2}{*}{$\mathrm{CHO}(\mathrm{mg} / \mathrm{dl})$} & 15 & $53.677 \pm 8.658$ & $34.340 \pm 5.435$ & $40.132 \pm 4.763$ & $60.038 \pm 7.556$ \\
\hline & 30 & $68.169 \pm 2.066$ & $60.110 \pm 5.177$ & $36.578 \pm 4.116^{* * * \# \#}$ & $29.585 \pm 2.251 * * * \# \# \#$ \\
\hline
\end{tabular}

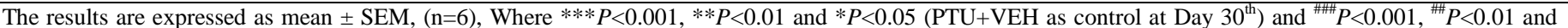

${ }^{\#} P<0.05\left(\mathrm{PTU}+\mathrm{LT}_{4}\right.$ as control at Day $\left.30^{\text {th }}\right)$, using Two-way RM ANOVA followed by a Bonferroni post test.

\section{DISCUSSION}

Various studies supported the presence of cardiac glycosides (Sinha et al. 2013), flavonoids, alkaloids (Ahmad et al. 1987, Sinha et al. 2013, Bhattacharjee et al. 2014), terpenoids and saponins (Rao et al. 2011) in stem bark of $C$. nurvala.

In this study, the ethanolic extract of $C$. nurvala was evaluated for it thyrotropic effect in PTU induced hypothyroidism, that is an antithyroid drug, that decline the thyroid hormone synthesis via inhibiting thyroid peroxidase (TPO), iodothyronine deiodinases type $\mathrm{I}$ (DIO1) that peripherally convert $\mathrm{T}_{4}$ to $\mathrm{T}_{3}$ (Bianco et al., 2002), in thyroid gland, liver etc. and inhibiting thyroid receptor (TR) mediated transcriptional activities at the glandular levels thus causing primary hypothyroidism i.e. reduced $\mathrm{FT}_{4}$ levels with concomitant increase in TSH (Moriyama et al., 2007; Geffner et al., 1975).

Out of the two selected doses, CNet 600 had shown significant thyrotropic activity via raising $\mathrm{FT}_{4}$ levels and reducing TSH levels. From previous studies, it was concluded that stimulation of Deiodonases (DIOs) reduces secretion of TSH (Baur et al. 2000). However, administration of CNet 400 raised the $\mathrm{FT}_{4}$, with concomitant increase in $\mathrm{TSH}$, which indicate that the lower dose, i.e. CNet 400 lack the stimulatory effect on DIO1 mediated $\mathrm{T}_{4}$ to $\mathrm{T}_{3}$ conversion inhibited by PTU. Similar study on Moringa oleifera and Aegle marmelos, also showed the extract raised the $\mathrm{T}_{4}$ levels but decreased $\mathrm{T}_{3}$ levels in female mice suggesting the inhibitory effect of extract on peripheral conversion of $\mathrm{T}_{4}$ to $\mathrm{T}_{3}$ (Tahiliani and Kar, 1999). However, not determining the $\mathrm{T}_{3}$ levels was limitation of our study.

An earlier study on lupeol and its ester lupeol linoleate, pentacyclic triterpenes derived from $C$. nurvala bark reduced the lipid abnormalities and hypercholesterolemia in rats fed with high cholesterol diet (Sudhahar et al. 2006). On the similar grounds in our study, both CNet 400 and CNet 600 containing triterpenes, shown reduction in cholesterol levels in comparison with $\mathrm{LT}_{4}$ treated group which can control CHO levels on long term therapy, along with dietary restriction and with use of hypolipidemic agents only (O'Brein et al., 1993; Tanis et al., 1996) and vehicle treated hypothyroid group. Mechanistically also, TH have been found to have crosstalk with other nuclear receptors including farnesoid $\mathrm{X}$ receptor (FXR), liver X receptor (LXR), peroxisome proliferatoractivated receptor (PPAR), and PPAR $\gamma$ coactivator (PGC- $1 \alpha)$ that regulate cholesterol levels indirectly (Oppenheimer et al., 1991; Liu and Brent, 2010).

\section{CONCLUSION}

The results of the present study indicates that in comparison with the standard treatment, i.e. levothyroxine, $\mathrm{CNet}$ $600 \mathrm{mg} / \mathrm{kg}$, showed stimulatory effects on the thyroid gland as evident from raised $\mathrm{FT}_{4}$ levels and decreased TSH levels alongwith significant reduction in cholesterol levels, suggesting its beneficial role in treating hypothyroidism, whereas, less marked and erratic response was shown by CNet $400 \mathrm{mg} / \mathrm{kg}$.

\section{ACKNOWLEDGEMENT}

This study was the part of M. Pharmacy (Pharmacology) thesis project. Authors greatly appreciate the support of all technical and non-technical staff of CT Institute of Pharmaceutical Sciences for providing their resources, facilities and guidance in completion of the study.

\section{REFERENCES}

Ahmad VU, Fizza K, Amber A, Arif S. Cadabicine and Cadabicine diacetate from Crataeva nurvula and Cadaba Farinosa. Journal of Natural Products, 1987; 50 (6): 1.

Baur A, Bauer K, Jarry H, Kohrle J. Effects of proinflammatory cytokines on anterior pituitary 5'-deiodinase type I and type II. J Endocrinol. 2000; 167:505-15

Bhattacharjee A, Shashidhara SC, Saha S. Neuroprotective activity of Crataeva nurvula Buch-Ham stem bark against Scopolamine induced cognitive impairment via antioxidative activites in rats. American Journal of Ethnomedicine, 2014; 1 (6): 371-83.

Biondi B, Fazio S, Carella C, Sabatini D, Amato G, Cittadini A, Bellastella A et al.. Control of adrenergic overactivity by beta-blockade improves the quality of life in patients receiving long term suppressive therapy with levothyroxine. The Journal of Clinical Endocrinology \& Metabolism 1994; 78 (5): 1028-33.

Botella-Carretero JI, Gal JM, Caballero C, Sancho J, EscobarMorreale HF. Quality of life and psychometric functionality in patients with differentiated thyroid carcinoma. Endocrine-related cancer 2003; 10 (4): 601-10

Daniel M, 2008. Medicinal Plants: Chemistry and Properties. Scientific publishers.

Garber JR, Cobin RH, Gharib H, Hennessey JV, Klein I, Mechanick JI et al. The American Association of Clinical Endocrinologists and American Thyroid Association Taskforce on Hypothyroidism in Adults KA. Clinical practice guidelines for hypothyroidism in adults: cosponsored by the American Association of 
Clinical Endocrinologists and the American Thyroid Association. Thyroid 2012; 22 (12): 1200-35

Geffner DL, Azukizawa M, Hershman JM. Propylthiouracil blocks extrathyroidal conversion of thyroxine to triiodothyronine and augments thyrotropin secretion in man. J. Clin. Invest. 1975; 55: 224-29

Haque ME, Islam MN, Gupta DD, Hossain M, Shekhar HU, Shibib BA. Triterpenoids from the stem bark of Crataeva nurvula. Dhaka Uni. J. Pharm. Sci. 2008; 7(1): 71-4

Hussain M, Bakhsh H, Aziz A, Majeed A, Khan IA, Mujeeb A, Farooq U. Comparative invitro study of antimicrobial activities of flower and whole plant of Jasminum officinale against some human pathogenic microbes. Journal of Pharmacy and Alternative Medicine, 2013; 2 (4), 3343

Jonklaas J, Davidson B, Bhagat S, Soldin SJ. Triiodothyronine levels in athyreotic individuals during levothyroxine therapy. Jama 2008; 299 (7): 769-77

Kaur A, Verma SK, Kalsi S, Neha. Hypothyroidism: Management based on Ayurvedic and modern therapeutic perspective. International Journal of Pharmaceutics \& Drug Analysis 2016; 4 (6): 2818 .

Khare CP. 2008. Indian medicinal plants: an illustrated dictionary. Springer Science \& Business Media.

Khattar V, Wal A. Utilities of Crataeva nurvala. International Journal of Pharmacy and Pharmaceutical Sciences 2012; 4 (4): $21-26$

Liu YY, Brent GA. Thyroid hormone crosstalk with nuclear receptor signaling in metabolic regulation. Trends Endocrinol Metab, 2010; 21: 166-73

Moriyama K, Tagami T, Usui T, Naruse M, Nambu T, Hataya $\mathrm{Y}$ et al. Antithyroid drugs inhibit thyroid hormone receptor-mediated transcription. The Journal of Clinical Endocrinology \& Metabolism 2007; $92(3): 1066-72$

Narayana A, Subhose V. Standardization of Ayurvědic formulations: a scientific review. Bull Indian Inst Hist Med Hyderabad, 2005 ; 35 (1): 21-32

O'Brein T, Dinneen SF, O'Brein PC, Palumbo PJ. Hyperlipidemia in Patients With Primary and Secondary Hypothyroidism. Mayo Clin Proc 1993; 68: 860-66

Oppenheimer JH, Schwartz HL, Lane JT, Thompson MP. Functional relationship of thyroid hormone-induced lipogenesis, lipolysis, and thermogenesis in the rat. J Clin Invest, 1991; 87: 125-132

Panda S, Kar A. Guggulu (Commiphora mukul) potentially ameliorates hypothyroidism in Female Mice. Phytotherapy Research, 2005;. 19: 78-80

Panda A, Rath S, Pradhan D, Mahanty A, Gupta BK, Bala NN. Hepatoprotective activity of leaves of Crataeva magna (Lour.) DC. In different types of Hepatotoxic rat models. Indo American Journal of Pharmaceutical Research, 2014; 4 (1): 125-31

Petersen K, Bengtsson C, Lapidus L, Lindstedt G, Nyström E. Morbidity, mortality, and quality of life for patients treated with levothyroxine. Archives of Internal Medicine 1990; 150 (10): 2077-81
Rao GV, Annamalai T, Mukhopadhyay T. Chemical examination and biological studies on the bark of Crataeva nurvula Buch.Ham. Phcog. J. 2011; 3 (20): 1-4

Razvi S, Weaver JU, Butler TJ, Pearce SH. Levothyroxine treatment of subclinical hypothyroidism, fatal and nonfatal cardiovascular events, and mortality. Archives of internal medicine 2012; 172 (10): 811-7

Rees-Jones RW, Larsen PR. Triidothyronine and thyroxine content of dessicated thyroid tablets. Metabolism 1977; 26 (11): 1213-18.

Ross DS. Bone density is not reduced during the short-term administration of levothyroxine to postmenopausal women with subclinical hypothyroidism: a randomized, prospective study. The American journal of medicine 1993; 95 (4): 385-8

Saravanan P, Chau WF, Roberts N, Vedhara K, Greenwood R, Dayan CM. Psychological well-being in patients on 'adequate'doses of 1-thyroxine: results of a large, controlled community-based questionnaire study. Clinical endocrinology 2002; 57(5): 577-85.

Schneider R, Schneider M, Reiners C, Schneider P. Effects of levothyroxine on bone mineral density, muscle force, and bone turnover markers: a cohort study. The Journal of Clinical Endocrinology \& Metabolism 2012; 97 (11): 3926-34. Clinical endocrinology 2002; 57 (5): $577-85$

Shelkea TT, Bhaskarb VH, Adkara PP, Jhaa U, Oswala RJ. Nephroprotective activity of ethanolic extract of stem barks of Crataeva nurvula Buch. Ham. International Journal of Pharmaceutical Sciences and Research, 2011; 2 (10):2712-17

Sikarwar MS, Patil MB. Antihyperlipidemic activity of Crataeva nurvula stem barks extracts. Indian Journal of Pharmaceutical Education and Research, 2012; 46 (4): 378-82

Sinha S, Mishra P, Amin H, Rah B, Nayak D, Goswami A, Kumar N, Vishwakarma R, Ghosal S. A new cytotoxic quinolone alkaloid and a pentacyclic steroidal glycoside from the stem bark of Crataeva nurvala: Study of antiproliferative and apoptosis inducing property. European Journal of Medicinal Chemistry, 2013; 60: 490-96

Sudhahar V, Kumar SA, Varalakshmi P. Role of lupeol and lupeol linoleate on lipemic - oxidative stress in experimental hypercholesterolemia. Lifesciences, 2006; 78; 1329-35

Tahiliani P, Kar A. Role of Moringa oleifera leaf extract in the regulation of thyroid hormone status in adult male and female rats Pharmacological research. 1999; 41(3): 319-23

Tanis BC, Westendorp RGJ, Smelt AHM. Differential Effects in the Rat of Thyroidectomy, Propylthiouracil and Other Goitrogens on Plasma Insulin and Thyroid Weight. Clinical Endocrinology 1996; 44: 643-49.

\section{How to cite this article:}

Kaur A, Khurana N, Verma SK. Potential Thyrotropic and Antihypercholesteronemic Activity Exhibited by Ethanolic Extract of Crataeva Nurvala Bark. J App Pharm Sci, 2017; 7 (11): 069073 